\title{
Epimerization of Cyclic Alanyl-Alanine in Basic Solutions
}

\author{
TORATANE MUNEGUMI ${ }^{1,2 *}$, TAKESHI FUJIMOTO², \\ MICHIOTAKADA ${ }^{2}$ and NOZOMINAGASHIMA ${ }^{2}$ \\ ${ }^{1}$ Department of Science Education, Naruto University of Education, Naruto, \\ Tokushima 772-8502, Japan. \\ ${ }^{2}$ Department of Materials Chemistry and Bioengineering, Oyama National College of Technology, \\ Oyama, Tochigi 323-0806, Japan. \\ http://dx.doi.org/10.13005/ojc/300103
}

(Received: November 30, 2013; Accepted: January 17, 2014)

\begin{abstract}
Alanine anhydrides (Cyclo-(Ala-Ala)) are the simplest dipeptides that have two chiral centers and three diastereomers: Cyclo-(L-Ala-L-Ala), Cyclo-(D-Ala-D-Ala), and Cyclo-(L-Ala-D-Ala).Analysis of the epimerization of these peptides may throw light on the development of homochirality in proteins. We show that the epimerization rate of Cyclo-(L-Ala-L-Ala) and Cyclo-(D-Ala-D-Ala) is higher than that of Cyclo-(L-Ala-D-Ala), while the ring-opening rates of Cyclo-(L-Ala-L-Ala) and Cyclo-(D-Ala-DAla) arelower than that of Cyclo-(L-Ala-D-Ala) in basic aqueous solutions. The total reaction resulted in the preferred stability of Cyclo-(L-Ala-L-Ala) and Cyclo-(D-Ala-D-Ala) to Cyclo-(D-Ala-L-Ala).
\end{abstract}

Key words: Cyclic dipeptide, Epimerization, Ring-opening reaction, Homochirality.

\section{INTRODUCTION}

Epimerization reactions produce diastereomers or epimers ${ }^{1}$, while racemization is the transformation between enantiomers. However, in some cases ${ }^{2-5}$,racemization has been used to meanboth racemization and epimerization. Epimerization and racemization in amino acids, peptides, and proteinshave been investigated from many viewpoints ${ }^{2-11}$. Epimerization of aspartic residues in proteins may sometimes increase thehydrophobicity of the proteins, because several diastereomeric peptides composed of D-aspartic residues show higher hydrophobicity than the original peptides composed of all L-amino acid residues ${ }^{10}$. A typical example is the epimerization in aspartic residue in a-crystalline form, although this epimerization is actually an inversion ${ }^{11}$.

Ionic mechanisms of racemization and epimerizationwere proposed by G. G. Smithand co-workers ${ }^{6,12-20}$, whoshowed that the rates of racemization of peptides were faster than those of free amino acids. However, this research wasmainly restricted to the epimerization of linear peptides and the racemization of 2,5-diketopiperazines bearing one chiral center, and did not consider cyclic diastereomeric peptides. Steinberg andOBada. 
showed that linear peptides containing isoleucine residue cyclizedto 2,5-diketopiperazines ${ }^{21}$. Cyclic dipeptides have been suggested as easily formed peptides in the chemical evolutionary process ${ }^{22}$ and important compounds in the development of homochirality $^{23}$, because of theireasy formation from amino acids and the difference between diastereomers in hydrophobicity. The topic of this research is the simple chiral cyclic dipeptides (cyclo(alanyl-alanine): Homo-L-CP (1) and Hetero-CP (2)) shown in Figure 1.In particular, the epimerization and ring-opening reactions are investigated in basic aqueous solutions. The epimerization of Homo-L-CP (1) and (3) will proceed at first from the hydrogen abstraction step to give solvated anion intermediates (4) and (5) ${ }^{15}$. These transform to their enantiomers. Among the intermediates (4), (5), and the cyclic dipeptides (Homo-L-CP (1), Hetero-CP (2), and Homo-D-CP (3)), push-pull transition states ${ }^{15}$ are suggested.

\section{EXPERIMENTAL}

\section{Chemicals}

A cyclic dipeptideCyclo-(L-Ala-LAla)(:Homo-L-CP (1)) and a racemic mixture containingCyclo-(L-Ala-L-Ala) (1), Cyclo-(L-Ala-LAla) (2), and Cyclo-(D-Ala-L-Ala) (3) were purchased from Sigma Chemicals Inc. Authentic linear peptides, L-Ala-L-Ala and D-Ala-L-Ala were prepared by the manner in the literature ${ }^{22}$.

\section{Instrumentation}

A Jasco high-performance liquid chromatograph composed of an 880-pump, 875-UV, and a reversed-phase analytical column: Lichrosorb R 100 RP-18 (250 × 4.6 mm I.D., Merck) was used for analyses. Elution was carried out with a mixture of water-acetonitrile $(97.5-2.5 \%(\mathrm{v} / \mathrm{v}))$ at a flow rate of $0.5 \mathrm{~mL} / \mathrm{min}$. The resulting chromatogram was recorded by means of a chromatocoda II. Figure 2 shows typical chromatograms of the reaction mixtures.

\section{Workup of reactions}

Homo-L-CP (1)15 mg (0.106 mmol) or an equivalent mixture composed of meso- and racemic cyclic Ala was dissolved in $20 \mathrm{~mL}$ of sodium hydroxide at different concentrations $(0.1 \mathrm{mM}, \mathrm{pH} 10.0$; 1.0mM, pH11.0; 2.5mM, pH11.4; 5.0mM,pH11.7;
10mM, pH12; 25mM; pH12.4; 50mM, pH12.7)at room temperature $\left(25^{\circ} \mathrm{C}\right)$. The sample solution was removed from the reaction mixture containing $5.3 \mathrm{mmol} / \mathrm{L}$ of cyclic dipeptidesat a selected time and analyzed usingthe HPLC described above. Detection was carried out at 210nm UV absorption.

\section{RESULTS AND DISCUSSION}

\section{Plausible early reactions of cyclic peptides}

The concentrations of the compounds illustrated in Figure1 can be determined in the equilibrium amongepimerization, ring-opening, and cyclization reactions. However, the earlier reactions of cyclic peptides (Homo-L-CP (1) and Hetero-CP (2)) may be shown more simply. The rate constant $k_{1}$ is much larger than the rate constant $k_{2}$, because the first pathway from Homo-L-CP (1) to L-Intermediate (3) is much slower than the second pathway from L-Intermediate (3) to Hetero-CP (2). Therefore, the first step is the rate-determining stepwhen calculating the approximate rate constant of the whole pathway from Homo-L-CP (1) to Hetero-CP (2).Moreover, the reaction pathways in the left and right sidesin Figure 1are symmetrical and can be simplified to the pathway in Figure 3.

Hetero and Homo mean homochiral and heterochiral, respectively; CP and LP mean cyclic peptide and linear peptide, respectively; DL and LD mean D-alanyl-L-alanine and L-alanyl-D-alanine, respectively.

\section{The reaction of Homo-L-CP (1) and Hetero-CP (3) in $1 \mathrm{mM} \mathrm{NaOH}$}

Figure 4 shows the time course of Homo-L$\mathrm{CP}$ (1) and Hetero-CP (3) in $1 \mathrm{mM} \mathrm{NaOH}$ at $25^{\circ} \mathrm{C}$. Both substrates were almost completely recovered and no other products were found on the chromatograms, even after 1500min. Cyclicdipeptides Homo-L-CP (1) and Hetero-CP (3) did not open their rings and did not epimerize at all in these conditions. The reaction of Homo-L-CP (1) and Hetero-CP (3) in 10mM NaOH

Figure 5 shows the time course of the reaction of Homo-L-CP (1) and Hetero-CP (3) in $10 \mathrm{mMNaOH}$ solution.

Linear peptides were detected up to only $1.3 \%$ at $160 \mathrm{~min}$, while cyclic peptides, Homo-L-CP 


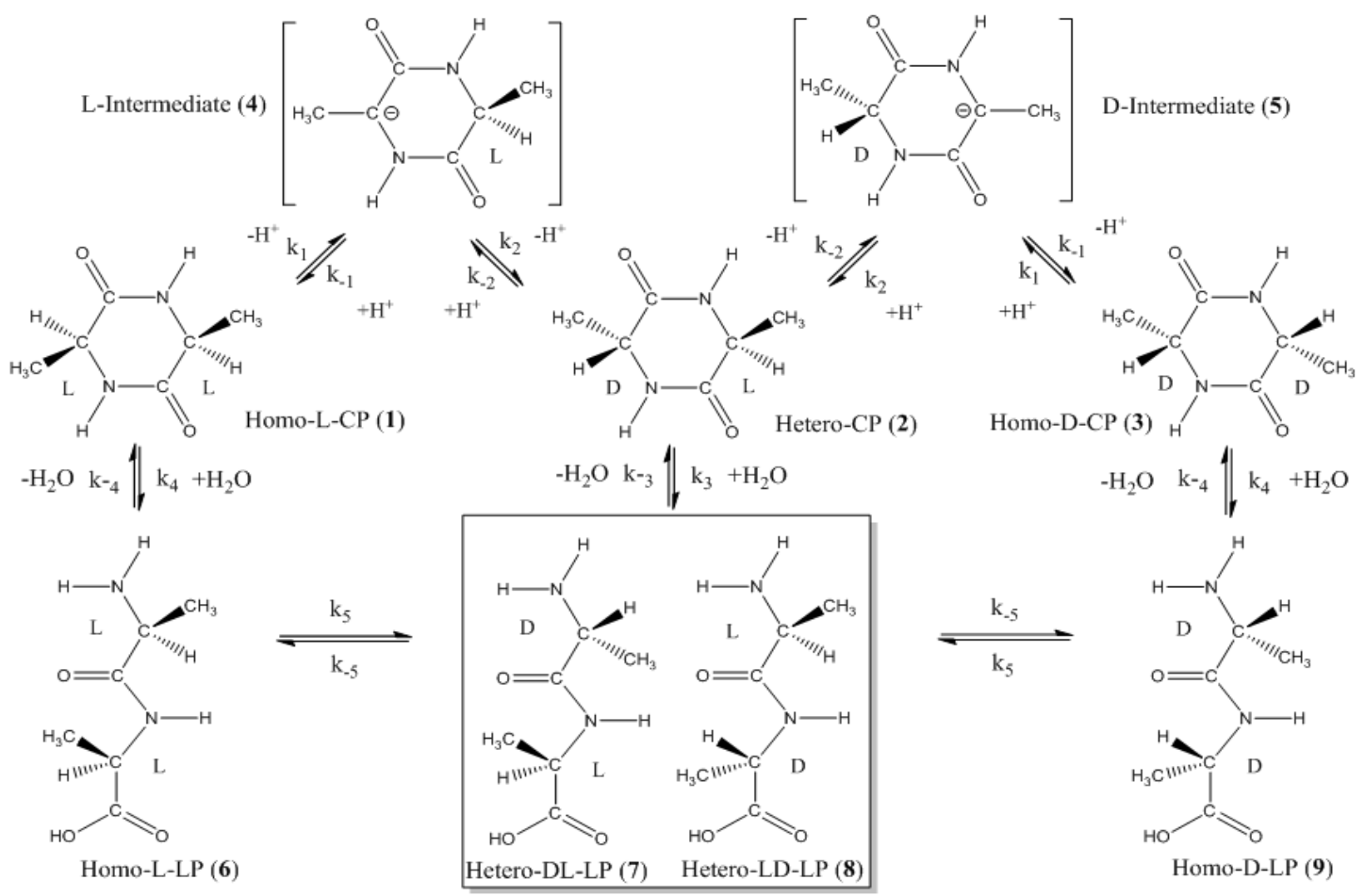

Fig. 1: Predicted mechanism of the epimerization and ring-opening reactions of cyclic-(Ala-Ala) in aqueous solutions. Hetero and Homo mean homochiral and heterochiral, respectively; CP and LP mean cyclic peptide and linear peptide, respectively; DL and LD mean D-alanyl-L-alanine and L-alanyl-D-alanine, respectively.

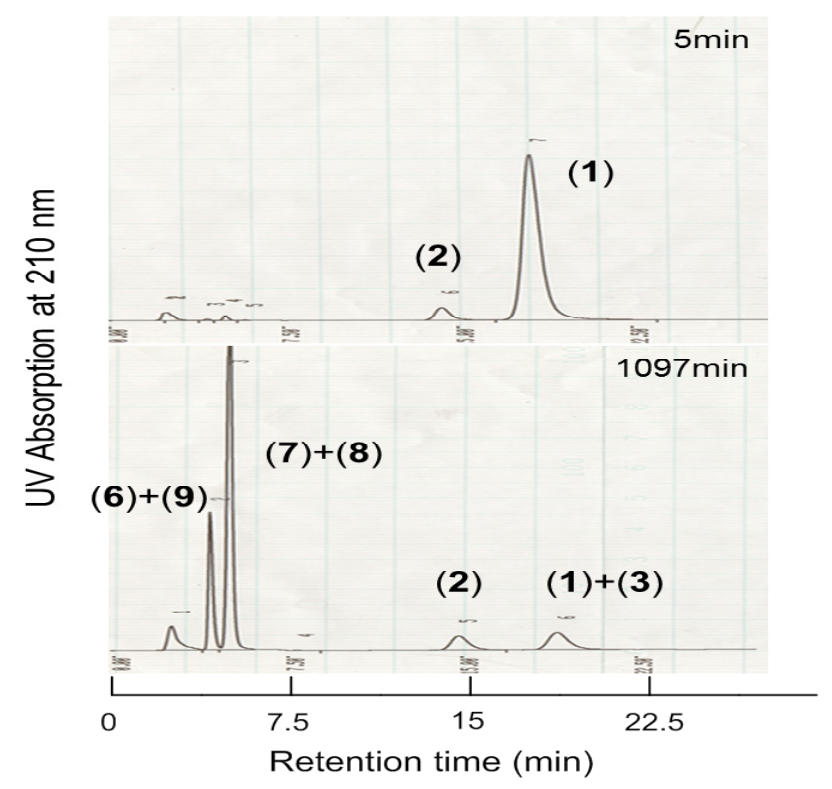

Fig. 2: Typical HPLC chromatograms of the reaction mixture of Homo-L-CP (1) at $5 \mathrm{~min}$ and $107 \mathrm{~min}$ in $0.05 \mathrm{M} \mathrm{NaOH.Column:} \mathrm{Lichrosorb} \mathrm{R} 100 \mathrm{RP}-18$ (250 × $4.6 \mathrm{~mm}$ I.D.); eluate: water-acetonitrile (97.5-2.5\% (v/v)) at a flow rate of $0.5 \mathrm{~mL} / \mathrm{min}$. Detection: $210 \mathrm{~nm}$ 



$$
\begin{array}{lll}
\mathrm{H}_{2} \mathrm{O} & \mathrm{k}-3
\end{array} \| \mathrm{k}_{3}+\mathrm{H}_{2} \mathrm{O}
$$
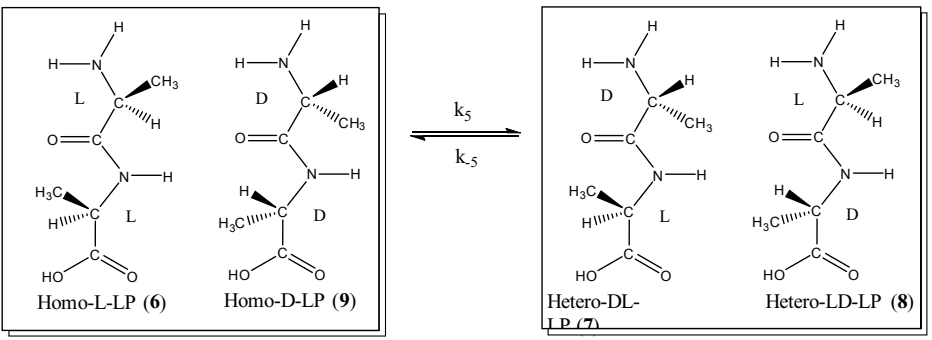

Fig. 3: The simplified pathway of epimerization, ring-opening, and cyclization reactions

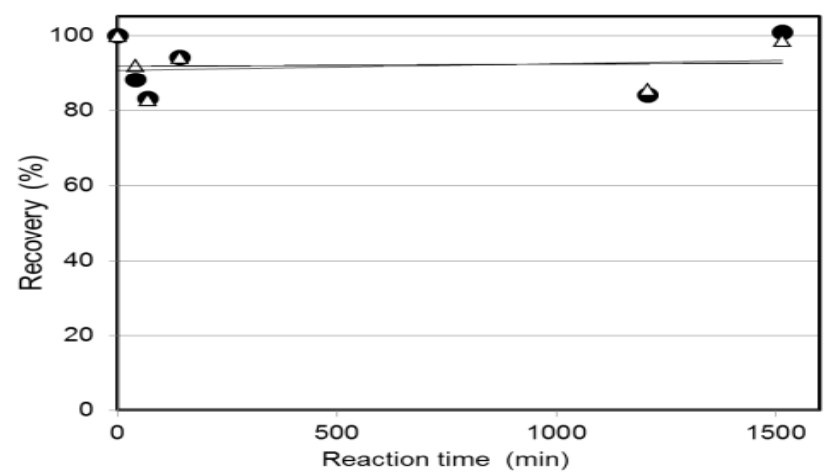

$\Delta$ : Homo-L-CP (1); : Hetero-LP (2).

Fig. 4.Time course of Homo-L-CP (1) and Hetero-CP (3) in $1 \mathrm{mM} \mathrm{NaOH}$ at $25^{\circ} \mathrm{C}$

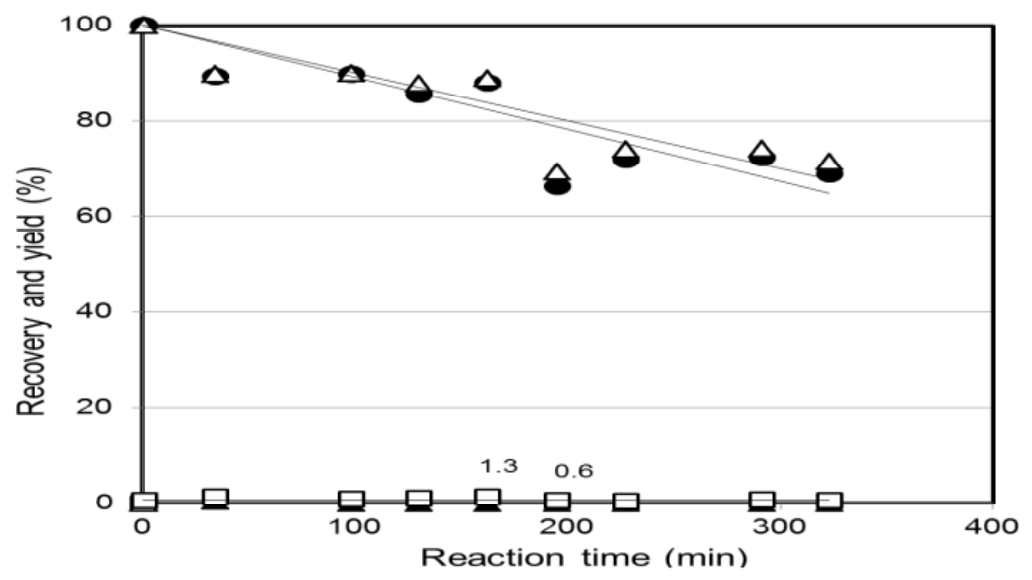

$\Delta$ : Homo-L-CP (1); • Hetero-CP (2); $\square$ : Homo-L-LP (6) plus Homo-D-LP (9); $\Delta$ : Hetero-LP (7) plus (8).

The percentages of totals of Homo-L-LP (6) plus Homo-D-LP (9) and Hetero-LP (7) plus (8) were calculated on the basis of the initial total amount of cyclic peptides (1) plus (2).

Fig. 5: Time course of Homo-L-CP (1) and Hetero-CP (3) in $10 \mathrm{mM} \mathrm{NaOH}$ at $25^{\circ} \mathrm{C}$ 
(1) and Hetero-CP (2) gradually decreased. Although some peaksemerged more quickly; they might be from the anion intermediate., epimerization and ring-opening reactions were not confirmed under this condition. However, the decrease in the concentration of Homo-L-CP (1) and Hetero-CP (2) cannot be explained by the increase of only the quickly eluted peaks. Other reactions like polymerization might explain the decrease of the reactants, but further investigation using other chromatography has to be carried out.

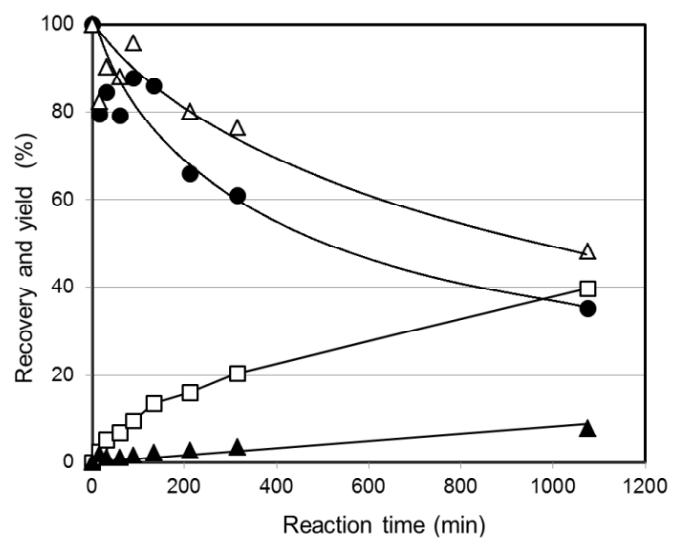

The reaction of Homo-L-CP (1) and Hetero-CP (3) in $25 \mathrm{mM} \mathrm{NaOH}$

The time course of a racemic mixture of Homo-L-CP (1) and Hetero-CP (3) is shown in Figure 6 (a), and the time course of Homo-L-CP is shown in Figure 6 (b).

In Figure 6 (a), Homo-L-CP (1) and Hetero$\mathrm{CP}$ (3) decreased gradually, but the decreasing rate of Hetero-CP (3) was larger than that of Homo-L-CP (1). After ca. 1100 min reaction, $50 \%$ of Homo-L-CP (1) and $35 \%$ of Hetero-CP (3) remained. Hetero-LP

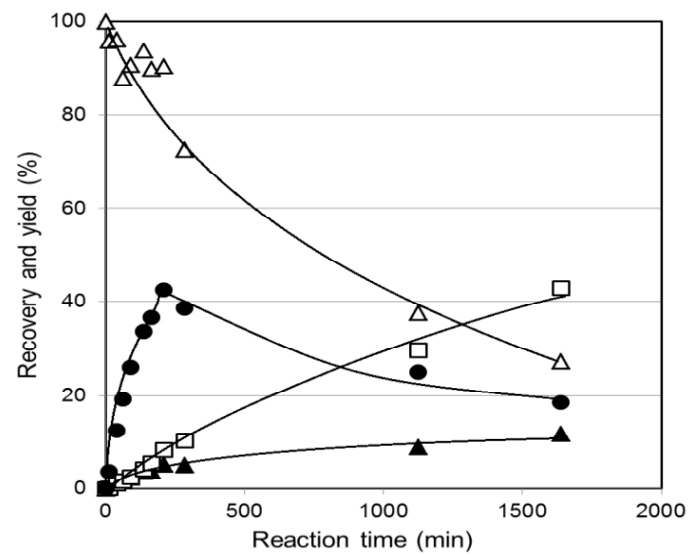

Fig. 6: Time course of the reactions of a racemic mixture containing Homo-DL-CP plus Hetero-CP (a) and Homo-L-CP (b) in $25 \mathrm{mM} \mathrm{NaOH}$ at $25^{\circ} \mathrm{C}$ : Homo-L-CP (1); : : Hetero-CP (2); $\square$ :Homo-L-LP (6) plus Homo-D-LP (9); $\Delta$ : Hetero-LP (7) plus (8). The percentages of totals of Homo-L-LP (6) plus Homo-D-LP (9) and Hetero-LP (7) plus (8) were calculated on the basis of the initial total amount of cyclic peptides (1) plus (2)
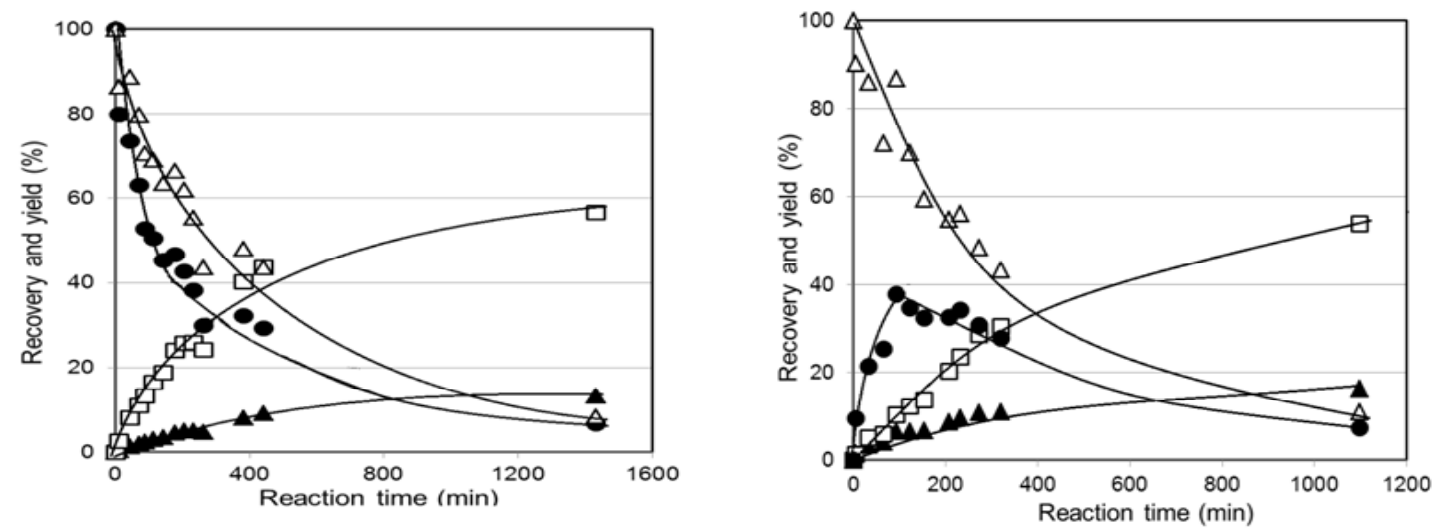

Fig. 7: The time course of the reactions of a racemic mixture containing Homo-DL-CP plus Hetero-CP (a) and Homo-L-CP (b) in $50 \mathrm{mM} \mathrm{NaOH}$ at $25^{\circ} \mathrm{C}$

$\Delta$ : Homo-L-CP (1); •: Hetero-CP (2); $\square$ : Homo-L-LP (6) plus Homo-D-LP (9); $\Delta$ : Hetero-LP (7) plus (8). The percentages of total of Homo-L-LP (6) plus Homo-D-LP (9) and Hetero-LP (7) plus (8) were calculated on the basis of the initial total amount of cyclic peptides (1) plus (2). 
(7) plus (8) and Homo-L-LP (6) plus Homo-D-LP (9) increased as the reaction time increased. However, Hetero-LP (7) plus (8) increased much more rapidly than Homo-L-LP (6) plus Homo-D-LP (9). The yields of the linear peptides were calculated from the total areas of heterochiral linear peptides (7) plus (8) and homochiral linear peptides (6) plus (9), because the peaks of the corresponding enantiomers could not be separated by using an achiral column (Lichrosorb).
The yields of these heterochiral and homochiral linear peptides were $40 \%$ and $8 \%$, respectively.

In Figure 6 (b), the initial reactant Homo-LCP (1) rapidly decreased and Hetero-CP (3) rapidly increased up to $43 \%$ at $200 \mathrm{~min}$. The increase of Hetero-CP (3) indicates the epimerization of HomoL-CP (1). However, Hetero-CP (3) decreased after $200 \mathrm{~min}$ to give $20 \%$ recovery at $1700 \mathrm{~min}$. The

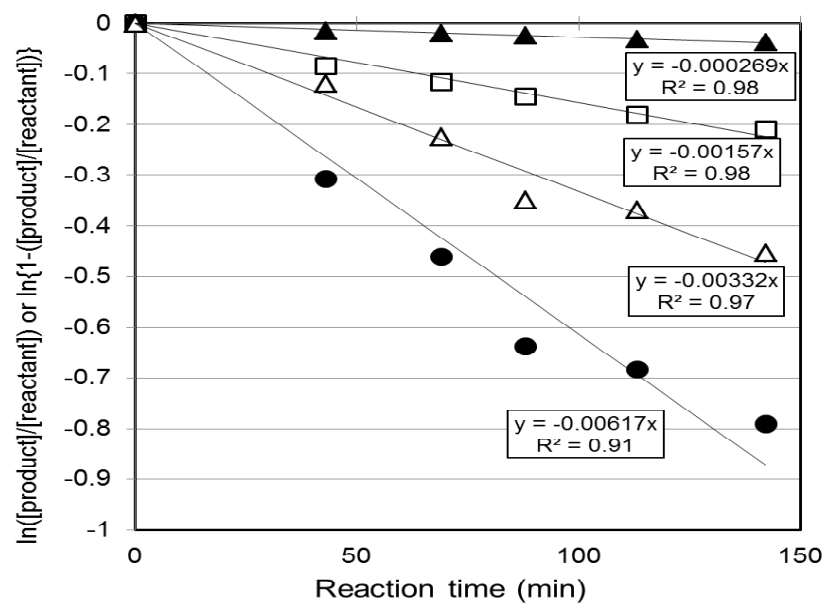

Fig. 8. Reaction rate constants of linear dipeptide formation and cyclic dipeptide decrease in 0.05 M NaOH. $\Delta$ : Homo-L-CP (1); • Hetero-CP (2); $\square$ : Homo-L-LP (6) plus Homo-D-LP

(9); $\Delta$ : Hetero-LP (7) plus (8).

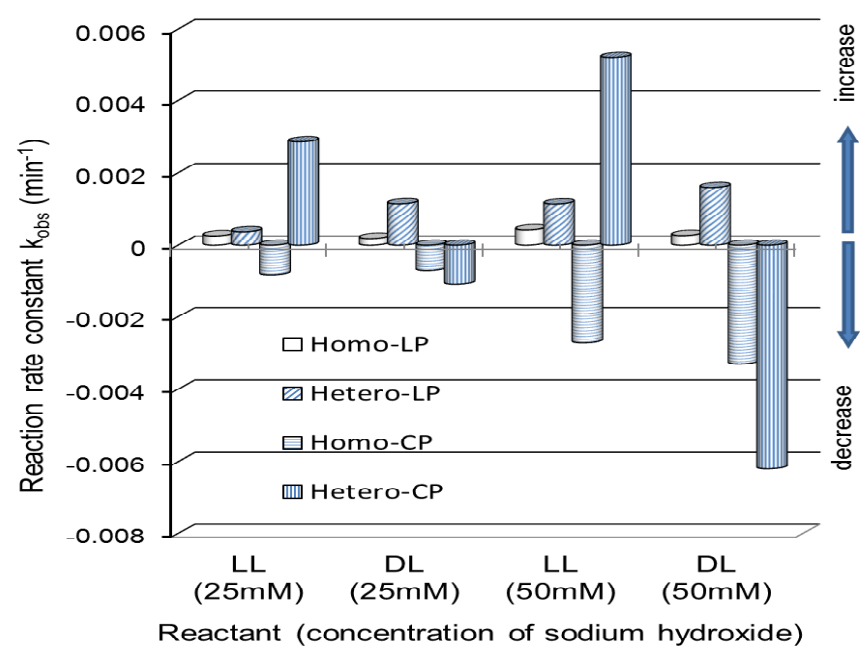

Fig. 9: Comparison of the reaction rate constants of the epimerization and ringopening reactions of Homo-CP and Hetero-CP in basic aqueous solutions. LL (25mM), DL

$(25 \mathrm{mM})$, LL $(50 \mathrm{mM})$, and DL $(50 \mathrm{mM})$ are the starting materials: Homo-L-CP in $25 \mathrm{mM}$ $\mathrm{NaOH}$, Hetero-CP in 25mM NaOH, Homo-L-CP in $50 \mathrm{mM} \mathrm{NaOH}$, Hetero-CP in 50mM NaOH 
decrease of Hetero-CP (3) suggests the ringopening to afford Hetero-LP (7) plus (8), which increased after 200min.

\section{The reaction of Homo-L-CP (1) and Hetero-CP (3) in $\mathbf{5 0} \mathrm{mM} \mathrm{NaOH}$}

Figure 7 (a) and (b) shows similar results to those of Figure $6(\mathrm{a})$ and (b), respectively.

Comparing the results in Figure 7 with those in Figure 6, the decrease of cyclic dipeptides and the increase of the linear dipeptides are faster than the results in Figure 6. This suggests that the reactions accelerated at high $\mathrm{pH}$.

\section{Comparison of the reaction rate constants}

Figure 8 shows the rate constant of the increase of linear dipeptides and the decrease of cyclic dipeptides in $50 \mathrm{mM} \mathrm{NaOH}$.

The vertical axis shows the inverse logarithm of the concentration of the product divided by the initial concentration of the reactant for Homo-L-CP (1) and Hetero-CP (2), and the inverse logarithm of 1 minus the concentration of the product divided by the concentration of initial reactant for Homo-L-LP (6) plus Homo-D-LP (9) and Hetero-LP (7) plus (8). The horizontal axis shows the reaction timein minutes. The plots in each reaction condition afford the pseudo-first-order reaction constants (observed rate constant $k_{\text {obs }}$ ) as the gradients of these lines.

The method shown in Figure 8 was also applied to the results at other $\mathrm{NaOH}$ concentrations to give Figure 9.

The negative circular cylinders show the decrease of the corresponding cyclic dipeptides, while the positive circular cylinders show the increase of cyclic dipeptides and linear dipeptides. For the reactions using Homo-L-CP, the increase of Hetero-CP may be induced by the epimerization of Homo-L-CP. The rate constants $\left(k_{\text {obs }}=0.0029 \mathrm{~min}^{-1}\right.$; $0.00521 / \mathrm{min}$ in $25 \mathrm{mM} \mathrm{NaOH}$ ) of the increase of Hetero-CP were about 1.9 times and 3.5 times larger than the rate constants $\left(k_{\text {obs }}=0.000821 / \mathrm{min} ; 0.0027\right.$ $1 / \mathrm{min}$ in $50 \mathrm{mM} \mathrm{NaOH}$ ) of the decrease of Homo-CP, respectively.
For the reactions using a racemic mixture composed of Homo-L-CP, Homo-D-CP, and Hetero$\mathrm{CP}$, the decrease of these cyclic dipeptides includes ringopening as well as epimerization from their diastereomers. The rate constants $\left(k_{\mathrm{obs}}=0.00111 /\right.$ $\mathrm{min} ; 0.00621 / \mathrm{min}$ in $25 \mathrm{mM} \mathrm{NaOH}$ ) of the decrease of Hetero-CP were about 1.5 times and 1.9 times larger than the rate constants $(0.000701 / \mathrm{min}$; $0.000331 / \mathrm{min}$ in $50 \mathrm{mM} \mathrm{NaOH}$ ) of the decrease of Homo-CP, respectively. However, the rate constant $\left(k_{\text {obs }}\right)$ represents the total of the epimerization and the ringopening of cyclic dipeptides.

On the other hand, the rate constant $\left(k_{\text {obs }}\right)$ of the increase of Hetero-LP was always larger (1.4 to 6.0 times) than that of Homo-LP. If the rate constants $\left(k_{5}\right.$ and $\left.k_{-5}\right)$ of the epimerization between linear dipeptides as well as the cyclization rate constants $\left(k_{-3}\right.$ and $\left.k_{-4}\right)$ are much smaller than those $\left(k_{3}\right.$ and $\left.k_{4}\right)$ of the ring-opening reactions, the rate constant $\left(k_{\text {obs }}\right)$ may be approximated by $k_{3}$ and $k_{4}$, respectively.We can therefore conclude that the rate constant $\left(k_{4}\right)$ of the ringopening of Hetero-CP is larger than that $\left(k_{3}\right)$ of Homo-CP.Under this assumption, the rate constant $\left(k_{1}\right)$ of the epimerization of Homo-CP may be larger than that $\left(k_{-1}\right)$ of Hetero-CP.

Although this research demonstrated that Homo-CP epimerizes faster than Hetero-CP and that Hetero-CP opens its ring faster than Homo$\mathrm{CP}$, more detailed consideration on the cyclization and epimerization of linear dipeptides may be necessary to determine the rate constants between dipeptides.

\section{CONCLUSION}

This research has demonstrated that Cyclo-(L-Ala-L-Ala) (: Homo-L-CP (1)) and Cyclo-(DAla-D-Ala)(: Homo-D-CP (3))epimerize faster than Cyclo-(L-Ala-D-Ala) (: Hetero-CP (2)), and that the rings of Cyclo-(L-Ala-L-Ala) (: Homo-L-CP (1)) and Cyclo-(D-Ala-D-Ala) (: Homo-D-CP (3))openmore slowly than those of Cyclo-(L-Ala-D-Ala) in $25 \mathrm{mM}$ and $50 \mathrm{mM} \mathrm{NaOH}$ solutions. The total reaction resulted in the preferred stability of Cyclo-(L-Ala-LAla) and Cyclo-(D-Ala-D-Ala)over Cyclo-(D-Ala-LAla) in these basic solutions. 


\section{REFERENCES}

1. M. B. Smith and J. March, March's Advanced Organic Chemistry: Reactions, Mechanisms, and Structure, $6^{\text {th }}$ edition, p. 169, Wiley \& Sons, Inc., Hoboken (2007).

2. K. A. Kvenvolden and E. Peterson, Science, 169: 1079-1082 (1969).

3. J. L. Bada, B. P. Luyenyk, and J. B. Maynard, Science, 170: 730-732 (1970).

4. J. Wehmiller and P. E. Hare, Science, 173: 907-911 (1971).

5. W. T. Smith Jr., Science, 172: 403 (1971).

6. K. M. Williams and G. G. Smith, Origins of Life and Evolutionary Biosphere, 8: 91-144 (1977).

7. N. Kriausakul and R. M. Mitterer, Science, 201: 1011-1014 (1978).

8. J. Csapo, Z. Csapo-Kiss, S. Nemethy, S. Folestad, A. Tivesten, and T. G. Martin, Amino Acids, 7: 317-325 (1994).

9. H. Brucker and N. Fujii, eds., D-Amino Acids in Chemistry, Life Science and Biotechnology, Wiley-VCH, Zurich (2011).

10. N. Fujii, Y. Momose, N. Ishii, M. Takita, M. Akaboshi, and M. Kodama, Mechanisms of Aging and Development, 107: 347-358 (1999).

11. T. Munegumi, Chemistry \& Biodiversity, 7: 1670-1679 (2010).

12. G. G. Smith and B. S. De Sol, Science, 207: 765-767 (1980).
13. G. G. Smith, K. M. Williams, and D. M. Wonnacott, Journal of Organic Chemistry, 43: 1-5 (1978).

14. G. G. Smith, A. Khatib, and G. S. Reddy, Journal of American Chemical Society, 105: 293-295 (1983).

15. G. G. Smith and T. Sivakua, Journal of Organic Chemistry, 48: 628-634 (1983).

16. E. D. Stroud, D. J. Fife, and G. G. Smith, A method for the determination of the pKa of the a-hydrogen in amino acids using racemization and exchange studies, Journal of Organic Chemistry, 48: 5368-5369 (1983).

17. R. Baum and G. G. Smith, Journal of American Chemical Society, 108: 7325-7327 (1986).

18. G. G. Smith, R. C. Evans, and R. Baum, Journal of American Chemical Society, 108: 7327-7332 (1986).

19. G. G. Smith and R. Baum, Journal of Organic Chemistry, 52: 2248-2255 (1987).

20. G. G. Smith and G. V. Reddy, Journal of Organic Chemistry, 54: 4529-4535 (1989).

21. S. Steinberg and J. L. Bada, Science, 213: 544-545 (1981).

22. T. Munegumi and A. Shimoyama, Chirality, 15S: 108-115 (2003).

23. U.Shanker, B. Bhushan, G. Bhattacharjee, and Kamaluddin, Origins of Life and Evolutionary Biosphere, 42: 31-45 (2012). 